\title{
Microstructure and Magnetic Properties of FePt-MgO Multilayer Thin Films
}

\author{
J.E. Wittig, ${ }^{*}$ Y. Fu, ${ }^{*}$ J. Bentley, ${ }^{* *}$ N.D. Evans, ${ }^{* *}$ and B. Lu*** \\ * Department of Electrical Engineering, Vanderbilt University, Nashville, TN 37235 \\ ** Metals \& Ceramics Div., Oak Ridge National Laboratory, PO Box 2008, Oak Ridge, TN 37831 \\ *** Seagate Technology, 2403 Sidney Street, Suite 550 Pittsburgh, PA 15203
}

FePt alloys with the $\mathrm{L}_{0}(\mathrm{CuAuI})$ ordered structure are important magnetic materials, since their large uniaxial-magnetocrystalline anisotropy $\left(\mathrm{Ku} \sim 7 \times 10^{6} \mathrm{~J} / \mathrm{m}^{3}\right)$ provides thermal stability for nanoscale single-domain particles. As-sputtered FePt thin films have a face-centered cubic (FCC) structure and are superparamagnetic at nanometer grain sizes. To increase the magnetocrystalline anisotropy and coercivity requires chemical ordering into the $\mathrm{L} 1_{\mathrm{o}}$ structure by annealing the material at 550 to $700^{\circ} \mathrm{C}$ [1]. The degree of ordering and improvement in magnetic properties depends upon the annealing time and temperature, e.g., annealing FePt nanocrystals at $600^{\circ} \mathrm{C}$ for one hour has produced coercivity greater than $19 \mathrm{kOe}$ [2]. An additional aspect of using FePt as magnetic recording media is the orientation distribution of the axis of easy magnetization. The ideal configuration is a strong crystallographic texture with alignment of the $\mathrm{L}_{\mathrm{o}}$ [001] axis of easy magnetization normal to the substrate.

This study involves a series of five FePt-MgO multilayers sputtered at room temperature onto silicon substrates with the following configurations (with $\mathrm{X}=2,2.5,3,3.5$, and $4 \mathrm{~nm}$ ): $\mathrm{Si}+\mathrm{SiO}_{2} \backslash \mathrm{Seedlayer}$ $(\mathrm{MgO}, \mathrm{Ag} \sim 25 \mathrm{~nm}) \backslash(\mathrm{MgO} 6 \mathrm{~nm} \backslash \mathrm{FePt} \mathrm{X} \mathrm{nm})_{3} \mathrm{MgO} 6 \mathrm{~nm}$, all annealed at $700^{\circ} \mathrm{C}$ for $30 \mathrm{~min}$. Planview samples, produced by ion milling from the substrate side, were characterized with a Philips CM200-FEG and a Philips CM30 equipped with a Gatan imaging filter (GIF) to better understand the magnetic properties through structure-property correlations. For example, the coercivity of the annealed sample with the $2.5 \mathrm{~nm} \mathrm{FePt}$ repeat was $11.5 \mathrm{kOe}$ whereas for the thicker FePt repeat of 4 $\mathrm{nm}$ the coercivity was reduced to $6.5 \mathrm{kOe}$.

Electron diffraction is a powerful method to investigate the crystallographic texture of these thin films [3]. The selected-area diffraction (SAD) pattern in figure 1 and the high-resolution image in figure 2 indicate that annealing these FePt-MgO multilayers produces the preferred texture with the [001] direction normal to the thin film plane. Tilting the sample so that the electron beam is no longer normal to the thin-film plane changes the diffraction rings into arcs of intensity characteristic of a highly textured film. In addition to the texture evolution, annealing the multilayers at $700^{\circ} \mathrm{C}$ for 30 minutes results in the $\mathrm{L} 1_{\mathrm{o}}$ ordering transformation as shown by the (110) superlattice ring in the SAD pattern. In figure 3, the results of elemental mapping by energy-filtered TEM (conventional 3window, $30-\mathrm{eV}$ slits, collection half-angle $\beta=4.8 \mathrm{mrad}$ ) reveal the distribution of $\mathrm{Fe}$ and $\mathrm{O}$ in the annealed films. Interpretation of some aspects of the maps is not intuitive and would be more straightforward with the availability of Pt maps (e.g., by EDS spectrum imaging). Nevertheless, the Fe maps show the sample with the thicker 4-nm FePt repeat has a more continuous FePt layer than the sample with a 2.5-nm repeat. A more continuous FePt layer reduces the coercivity since the grains are exchange coupled and the switching mechanism is domain wall pinning. For the thinner FePt repeat, the annealed FePt-MgO multilayer behaves more like granular media, where magnetic grains switch coherently and individually [4].

[1] X. Sun et al., J. Appl, Phys. 93 (2003) 7337-7339.

[2] H. Zeng et al., Appl, Phys. Lett. 80 (2002) 2583-2585.

[3] B. Lu et al., J. Appl. Phys. 85 (1999) 4295-4297.

[4] Financial support from Seagate Technology is gratefully acknowledged (JEW, YF). Research at the ORNL SHaRE User Facility (JB, NDE) supported by the Division of Materials Sciences and Engineering, Office of Basic Energy Sciences, U.S. Department of Energy, under contract DEAC05-00OR22725 with UT-Battelle, LLC. 


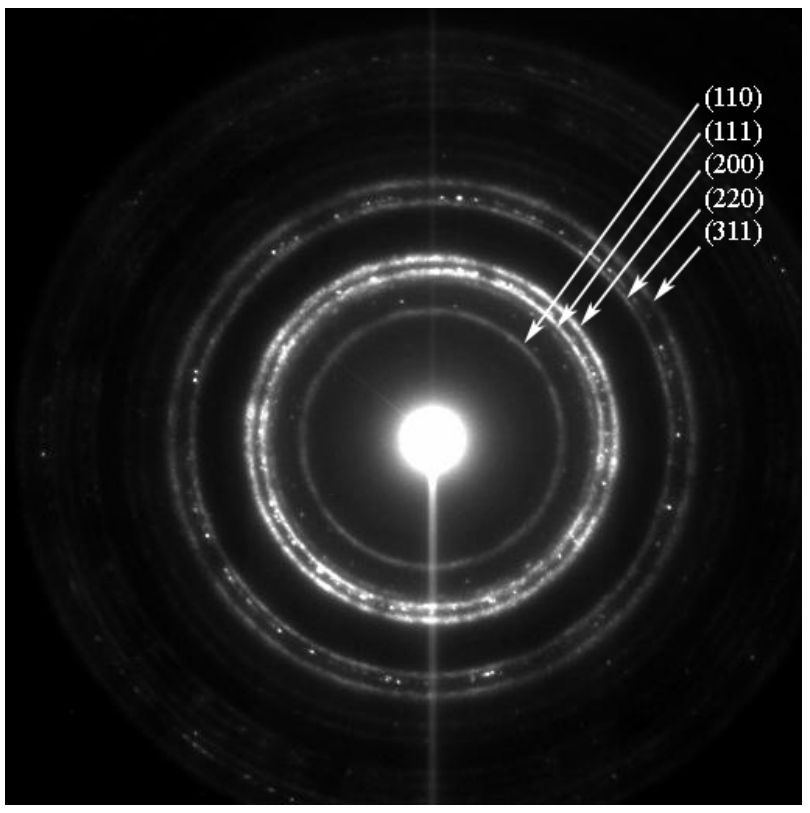

FIG. 1. Selected area diffraction pattern of FePt-MgO multilayer with $4 \mathrm{~nm} \mathrm{FePt}$ layers annealed at $700^{\circ} \mathrm{C}$ for $30 \mathrm{~min}$.

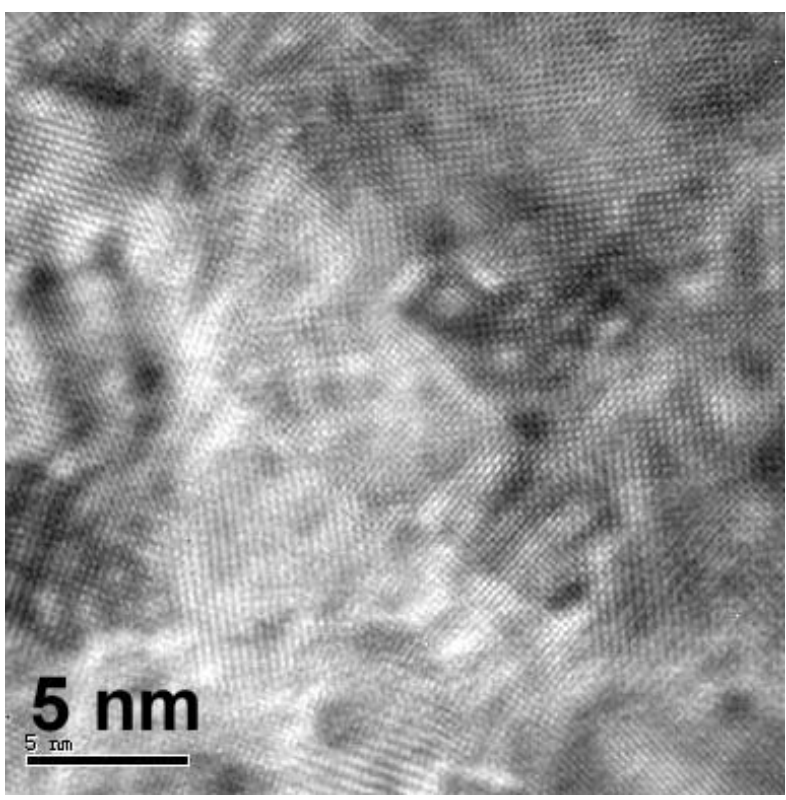

FIG. 2. High resolution image of FePt$\mathrm{MgO}$ multilayer with $4 \mathrm{~nm}$ FePt layers annealed at $700^{\circ} \mathrm{C}$ for $30 \mathrm{~min}$.
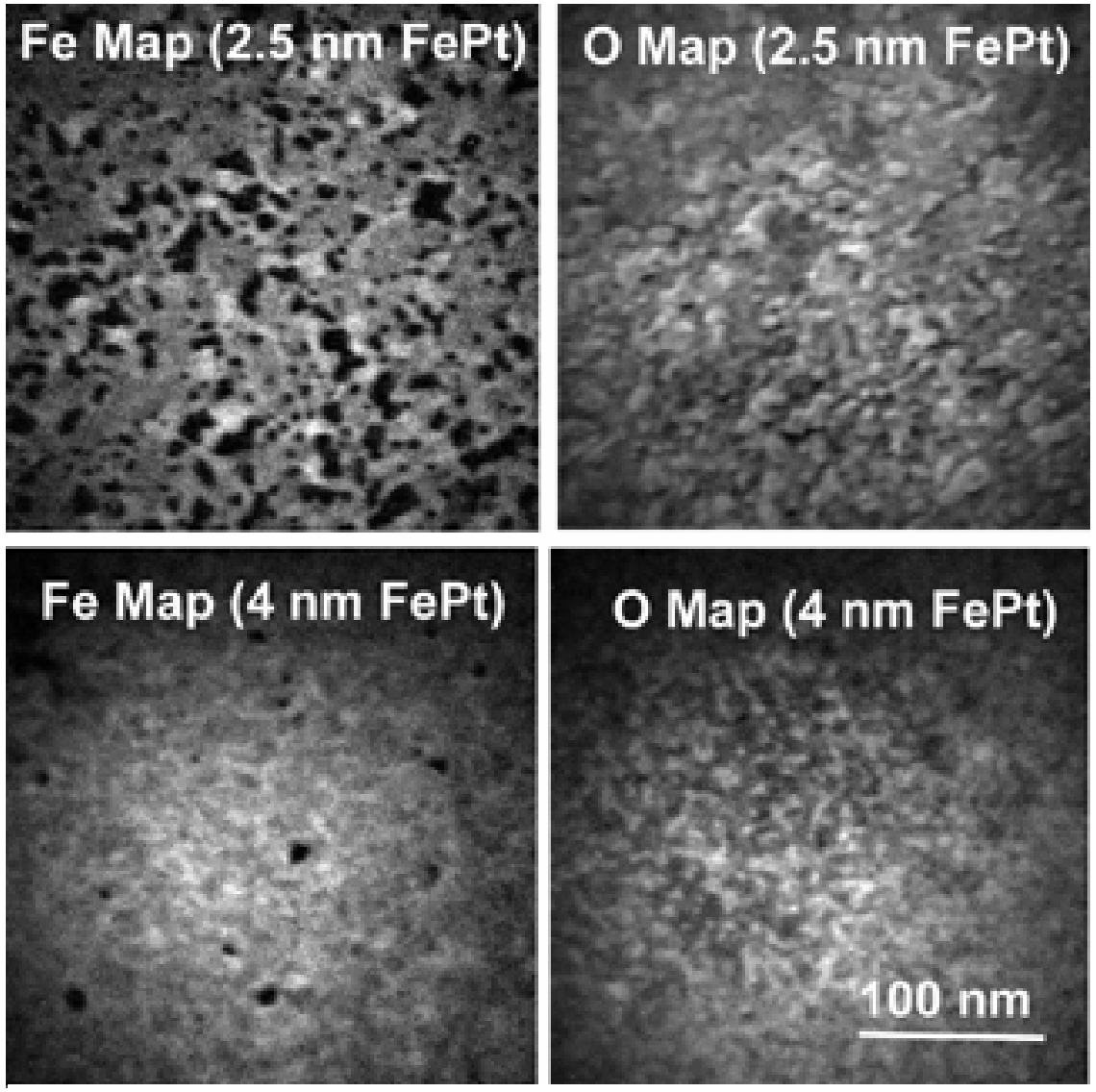

FIG. 3. Elemental EFTEM maps of the Fe and $\mathrm{O}$ distribution in the annealed FePt-MgO multilayer thin films. 